\title{
Pathways involved in pony body size development
}

\author{
Jun Fang ${ }^{\dagger}$, Dong Zhang ${ }^{\dagger}$, Jun Wei Cao ${ }^{\dagger}$, Li Zhang, Chun Xia Liu, Yan Ping Xing, Feng Wang, Hong Yang Xu, \\ Shi Chao Wang, Yu Ling, Wei Wang, Yan Ru Zhang ${ }^{*}$ and Huan Min Zhou*
}

\begin{abstract}
Background: The mechanism of body growth in mammals is poorly understood. Here, we investigated the regulatory networks involved in body growth through transcriptomic analysis of pituitary and epiphyseal tissues of smaller sized Debao ponies and Mongolian horses at the juvenile and adult stages.

Results: We found that growth hormone receptor (GHR) was expressed at low levels in long bones, although growth hormone $(G H)$ was highly expressed in Debao ponies compared with Mongolian horses. Moreover, significant downregulated of the GHR pathway components m-RAS and ATF3 was found in juvenile ponies, which slowed the proliferation of bone osteocytes. However, WNT2 and PLC 32 were obviously upregulated in juvenile Debao ponies, which led to premature mineralization of the bone extracellular matrix. Furthermore, we found that the WNT/C $\mathrm{C}^{2+}$ pathway may be responsible for regulating body growth. GHR was demonstrated by q-PCR and Western blot analyses to be expressed at low levels in long bones of Debao ponies. Treatment with WNT antagonistl decreased the expression of WNT pathway components $(P<0.05)$ in vitro. Transduction of ATDC5 cells with a GHR-RNAi lentiviral vector decreased the expression of the GHR pathway components $(P<0.05)$. Additionally, the expression of the IGF-1 gene in the liver was lower in Debao ponies than in Mongolian horses at the juvenile and adult stages. Detection of plasma hormone concentrations showed that Debao ponies expressed higher levels of IGF-1 as juveniles and higher levels of $\mathrm{GH}$ as adults than Mongolian horses, indicating that the hormone regulation in Debao ponies differs from that in Mongolian horses.
\end{abstract}

Conclusion: Our work provides insights into the genetic regulation of short stature growth in mammals and can provide useful information for the development of therapeutic strategies for small size.

Keywords: Growth hormone receptor, Debao pony, RNA-seq, Short stature

\section{Background}

Domestic animals' body size is a crucial index for determination of horse breeds and has become a priority factor in animal breeding. It is closely related to their physiological function, production performance, disease resistance and adaptability to the external environment $[1,2]$. Given the high value of this trait, in-depth investigations into its genetic aspects in domestic species have

\footnotetext{
*Correspondence: huanminzhou@263.net; yanru1964@163.com

†Jun Fang, Dong Zhang and Jun Wei Cao contributed equally to this work. College of Life Sciences, Inner Mongolia Agricultural University, No. 306 Zhaowuda Road, Hohhot 010018, China
}

been conducted. To date, molecular elements related to body size have been investigated in pigs and cows as well as in humans [3-8]. The related studies have indicated that SNPs in the GH1 gene [3] and haplotypes with a long sweep on X chromosome [4] are associated with body size in pigs. The growth pattern of body and organ in pigs with growth hormone receptor $(G H R)$ knockout mutations are similar to those in human with Laron syndrome, which is a rare and autosomal recessive disorder caused by loss-of-function mutations in the GHR gene [5]. Cattle with the haplotype combination H3H3 (CCGG-CC-AA-CC) which varied in the STAT3 gene

C The Author(s). 2021 Open Access This article is licensed under a Creative Commons Attribution 4.0 International License, which permits use, sharing, adaptation, distribution and reproduction in any medium or format, as long as you give appropriate credit to the original author(s) and the source, provide a link to the Creative Commons licence, and indicate if changes were made. The images or other third party material in this article are included in the article's Creative Commons licence, unless indicated otherwise in a credit line to the material. If material is not included in the article's Creative Commons licence and your intended use is not permitted by statutory regulation or exceeds the permitted use, you will need to obtain permission directly from the copyright holder. To view a copy of this licence, visit http://creativecommons.org/licenses/by/4.0/ The Creative Commons Public Domain Dedication waiver (http://creativecommons.org/publicdomain/zero/1.0/) applies to the data made available in this article, unless otherwise stated in a credit line to the data. 
promoter regions is significantly enhanced body size than that with haplotype combination H1H1 (AA-AAAA-AA-TT) and H2H3 (CC-GG-AC-GA-CC), respectively [6]. Whole-genome sequence analysis has shown that the genetic architecture of stature in cattle is similar to that in humans [7]. However, many more heightrelated genes have been identified in humans than in these other mammals [8].

Like all domestic animals, horses have evolved into many different populations with widely varying body sizes through natural and artificial selection. A few studies on the genetic aspects of body size in horses have been conducted. For example, a genome-wide association study based on SNPs identified two chromosomal loci near the LCORL/NCAPG gene and the ZFAT gene that have already been shown to influence body height in humans [9]. In addition, a whole-genome sequencing study on two miniature Shetland ponies and one standard-sized Shetland pony revealed four synergistic variants including in ADAMTS17, OSTN, GHI and $H M G A 2$ that limit wither height to $87 \mathrm{~cm}$ and seemingly reveal the main reason for the short stature of miniature ponies [10]. A complementary genome analysis of ponies and tall horses identified the genomic loci related to body height and metabolic traits and discovered that HMGA2 c.83G > A (p.G28E) variants were significantly altered in Welsh ponies, suggesting that the highly related loci in the ponies were highly efficient in altering metabolic pathways [11]. However, body size is a complex quantitative trait controlled by multiple genes. Thus, the molecular pathways regulating body height in horses remain unclear.

Body size depends largely on long bone growth and endocrine hormone signaling. Bones themselves, as well as other endocrine organs can act synergistically to promote growth $[12,13]$. In this study, we sequenced the transcriptomes of the pituitary gland and long bone tissues from Debao ponies (DPs) and Mongolian horses (MHs). The DP and $\mathrm{MH}$ are registered standard native horse breeds in China. The DP, which is less than 106 $\mathrm{cm}$ in height, originated in Debao County in the Guangxi Zhuang Autonomous Region of southwestern China and is well adapted to the local mountain environment. The MH, which is $122 \mathrm{~cm}$ to $142 \mathrm{~cm}$ in height, is one of the oldest horse breeds inhabiting the Mongolian Plateau; this breed is adaptable and exhibits strong disease resistance and hardiness on rough terrain [14, 15]. Previous reports have indicated that the DP has a genetic relationship with the $\mathrm{MH}$ [16] although both populations have undergone long-term natural and artificial selection over the course of their evolution that has resulted in significant differences in height. However, little is known about the molecular mechanism determining the body size of DPs. Hence, we systematically screened the key genes involved in the regulatory network of growth body size to reveal the correlation between the expression patterns of candidate genes and body size traits and to further elucidate the molecular pathways influencing body size.

\section{Results \\ Identification of differentially expressed genes (DEGs) in DPs}

Height analysis revealed obvious differences between DPs and MHs. DPs exhibited no significant differences in height between the juveniles (less than 3 years) and adults (more than 3 years) stages, while MHs did exhibit significant differences in height. DPs reached an the adult height at an early age, and the body length, chest circumference, canon bone circumference, neck length and head length increased similarly to the body height (Table 1). DPs and MHs exhibited significant differences in body height at the juvenile stage $(P<0.05)$ and at the adult stage $(P<0.005)$ (Additional file 1$)$.

We constructed and sequenced an RNA-seq library from 24 samples of pituitary and epiphyseal tissues taken from three DPs and three MHs at the juvenile and adult stages (Fig. 1a), as these tissue types are related to body size development $[12,13]$. A total of 11,344 DEGs were obtained by RNA-seq, of which 7436 were differentially expressed between the two breeds at the same stage (juvenile or adult). Specifically, 2761 and 563 DEGs in the pituitary and 1908 and 2204 DEGs in the long bone epiphysis were identified between MHs and DPs at the juvenile and adult stages, respectively. In addition, 3958 genes were differentially expressed between the different developmental stages in the same breed; 1358 and 970 DEGs were identified in the MH pituitary and long bone epiphysis, while 1018 and 562 DEGs were identified in the DP pituitary and long bone epiphysis, respectively (Fig. 1b). The sample correlation results showed that the pituitary samples were clusterd together independent of breed and developmental stage, while almost all long bone samples (except MH adult sample 4) were clustered by breed (Additional file 2). Cluster analysis of the different developmental stages of DPs and MHs showed significant differences between pituitary and epiphyseal tissues in the two breeds at the two developmental stages (Fig. 1c).

Significant differences were found in matrix metalloproteinases (MMPs) and collagen in long bone tissues between adult and juvenile horses. Greater enrichment of relevant pathways was observed at the juvenile stage than at the adult stage. However, the MAPK signaling pathway was less enriched at the juvenile stage than at the adult stage. In addition, significant differences were found in the WNT signaling pathway, the PI3K-Akt signaling pathway, cell junctions and cell surfaces in the 
Table 1 Height Data from Debao Ponies and Mongolian Horses

\begin{tabular}{lllllllll}
\hline NO. & $\begin{array}{l}\text { Age } \\
\text { (year) }\end{array}$ & Sex & $\begin{array}{l}\text { Height } \\
(\mathbf{m})\end{array}$ & $\begin{array}{l}\text { Body length } \\
(\mathbf{m})\end{array}$ & $\begin{array}{l}\text { Bust } \\
(\mathbf{m})\end{array}$ & Canon bone circumference $(\mathbf{m})$ & $\begin{array}{l}\text { Neck circumference } \\
(\mathbf{m})\end{array}$ & $\begin{array}{l}\text { Head circumference } \\
(\mathbf{m})\end{array}$ \\
\hline Pony1 & 1 & female & 1 & 0.95 & 1.1 & 0.13 & 0.49 & 0.4 \\
Pony2 & 1 & female & 0.93 & 0.93 & 0.94 & 0.12 & 0.35 & 0.4 \\
Pony3 & 1 & female & 1 & 0.93 & 1.02 & 0.14 & 0.37 & 0.37 \\
Pony4 & 4 & female & 0.94 & 0.82 & 0.97 & 0.12 & 0.4 & 0.35 \\
Pony5 & 5 & female & 0.88 & 0.85 & 0.94 & 0.13 & 0.44 & 0.36 \\
Pony6 & 4 & female & 0.97 & 0.85 & 0.99 & 0.13 & 0.65 & 0.4 \\
Horse1 & 1 & female & 1.27 & 1.29 & 1.4 & 0.06 & 0.65 & 0.52 \\
Horse2 & 1 & female & 1.25 & 1.32 & 1.46 & 0.07 & 0.61 & 0.55 \\
Horse3 & 1 & female & 1.24 & 1.25 & 1.39 & 0.07 & 0.66 & 0.52 \\
Horse4 & 4 & female & 1.35 & 1.28 & 1.69 & 0.07 & 0.71 & 0.53 \\
Horse5 & 4 & female & 1.37 & 1.43 & 1.6 & 0.07 & 0.73 & 0.54 \\
Horse6 & 4 & female & 1.43 & 1.48 & 1.74 & 0.06 & & 0.53 \\
\hline
\end{tabular}

pituitary glands between adult and juvenile horses (Fig. 1d). This finding suggests that in DPs, the MAPK signaling pathway may participate in limiting long bone growth at the juvenile stage.

As shown in the Venn diagram, 82 DEGs in the long bone epiphysis overlapped between the two breeds of horses at different stages, while 266 DEGs in pituitary tissue overlapped (Fig. 2a). The volcano plot shows that $G H$ and TSHB were significantly upregulated in the pituitary tissues of juvenile DPs and MHs, while GHR was significantly downregulated in the long bones of juvenile DPs and MHs. GHR expression was significantly lower in DPs than in MHs. In addition, the expression of genes related to the epiphyseal cell matrix, such as $A L P L, C O L$ and $M M P$ was significantly higher in MHs than in DPs, while the expression of GH, TSH and IGF-1 in the pituitary was significantly higher in juvenile DPs than in juvenile MHs (Fig. 2b).

\section{DPs exhibit excessive $G H$ expression and low $G H R$ expression}

$G H$ expression and GHR expression were differed significantly in the tissues of the two breeds (Fig. 2c). GH expression in the juvenile DP pituitary (DPPJ) was 13fold higher than that in the juvenile $\mathrm{MH}$ pituitary (MHPJ) (Additional file 3). Although GHR expression in the juvenile DP long bone (DPLBJ) was 1.4-fold lower than that in the juvenile MH long bone (MHLBJ) (Additional file 4). Analysis of protein levels showed that GH expression in the pituitary tissue was higher in DPs than that in MHs at both stages, although this difference was not found in long bone tissues (Additional file 5). Thus, we found that DPs have high expression of $G H$ and low expression of GHR. Low expression of GHR may lead to GH insensitivity. Previous studies have shown that idiopathic dwarfism is associated with extremely low expression of GHR $[17,18]$. Thus, we hypothesized that the low expression of GHR may be related to the small size of DPs.

$\mathrm{GH}$ is synthesized and secreted mainly by GH cells in the anterior pituitary and is very important for the growth and development of bone and the maintenance of bone mass. When GH and GHR are expressed simultaneously, they act on target cells through a corresponding signaling pathways (Fig. 2d). Through analysis of the coexpression network linking $G H$ and $G H R$, we found that many genes related to extracellular matrix (ECM) development were associated with these cellular signaling pathways (Fig. 2e).

GH stimulates the production of IGF-1, and IGF-1 acts as a surrogate marker for $\mathrm{GH}$. The results of this study revealed that the expression of IGF-1 was higher in the liver in MHs than in DPs at both the adult and juvenile stages (Additional file 6). In addition, GH expression was extremely high in the DP pituitary of DPs compared with the pituitary of MHs at the juvenile stage $(P<0.001)$ (Fig. 3a). Transcript levels alone are not sufficient to predict protein levels in many situations. In additon, other hormones have been shown to be different in the two horse breeds. For example, common glycoprotein alpha (CGA) and TSHB are positively and negatively regulated by triiodothyronine (T3), respectively. We found no significant differences in CGA or TSHB expression between adult DPs and MHs; however, the opposite result was observed in juvenile horses (Fig. 3b, c).

To determine the effects of additional relevant hormones on the body height of DPs, the concentrations of T3, T4, IGF-1, GH and TSH in plasma were determined by radioimmunoassay. Plasma hormone concentrations differed significantly among the groups. The T3 and T4 concentrations were higher in adult MHs than in DPs $(P<0.001)$, but did not differ at the juvenile stage in 
a

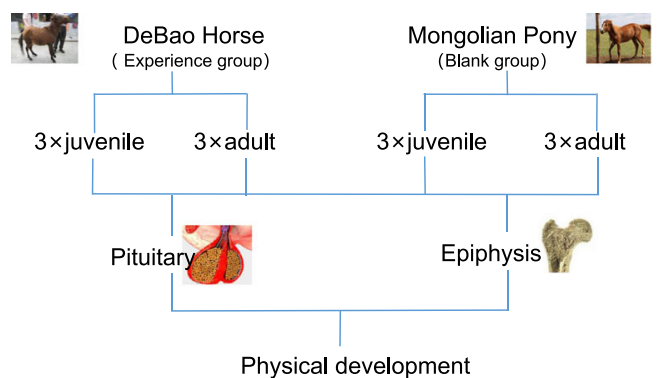

C
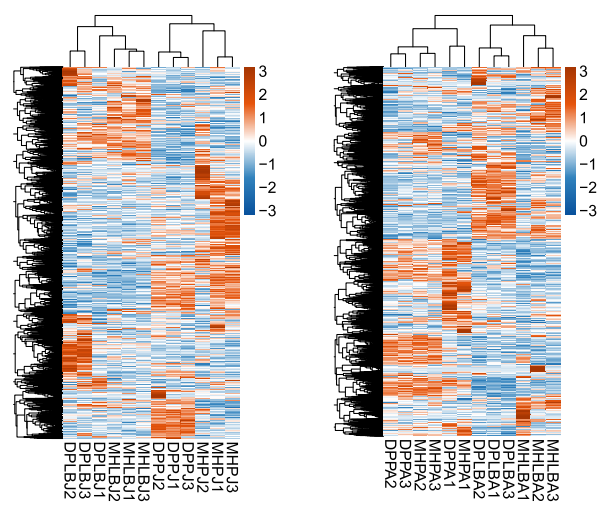

b

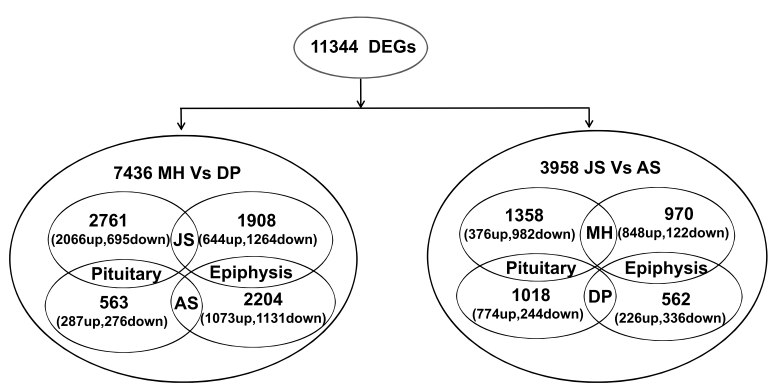

d
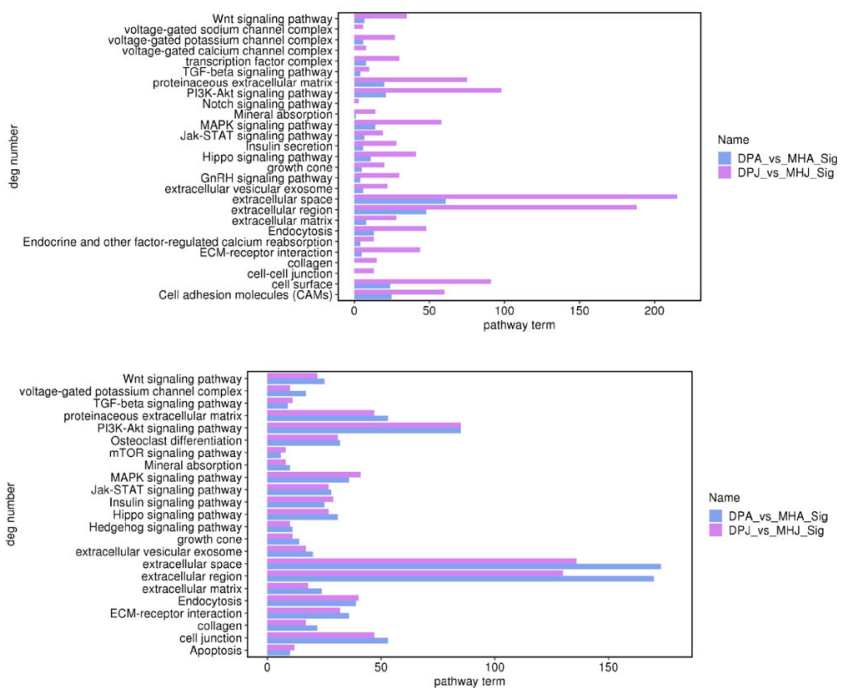

Fig. 1 Summary of high-throughput sequencing data for the Debao pony (DP) and Mongolian horse (MH). a Schematic of the DP and MH groups. b Numbers of genes up/downregulated in the two breeds of horses at the two developmental stages (JS vs AS, juvenile stage vs adult stage). c Cluster analysis of the different developmental stages of DPs and MHs. The overall hierarchical clustering map based on FPKM values was generated with the $\log 10($ FPKM +1$)$ values. Red indicates strongly expressed genes, and blue indicates weakly expressed genes. The colors from red to blue indicated log10 (FPKM + 1) values from large to small. $\mathbf{d}$ GO and KEGG enrichment results for the DEGs in the MHPA vs DPPA and MHLBJ vs DPLBJ comparisons. MHPJ, juvenile Mongolian horse pituitary; MHPA, adult Mongolian horse pituitary; MHLBJ, juvenile Mongolian horse long bone; MHLBA, adult Debao pony long bone; DPPJ, juvenile Debao pony pituitary; DPPA, adult Debao pony pituitary; DPLBJ, juvenile Debao pony long bone; DPLBA, adult Debao pony long bone

these two breeds; the T3 and T4 concentrations in adult MHs were significantly higher than those in juvenile MHs $(P<0.001)$, while those in DPs displayed the opposite trend; and the TSH content in juvenile DPs was lower than that in MHs $(P<0.01)$ (Fig. 3d). Moreover, the concentrations of $\mathrm{GH}$ and IGF-1 differed between the two horse breeds at the juvenile stage. In DPs, the IGF-1 and the GH concentrations were higher in juveniles than in adults $(P<0.01$ and $P<0.001$, respectively). However, in MHs, the plasma concentration of $\mathrm{GH}$ in juveniles was similar to that in adults, while the IGF-1 concentration was higher in adults $(P<0.001)$ (Fig. 3e). The different changes in hormone concentrations between these groups indicated that these genes may play an important role in the hypothalamus in regulating body size.
In vitro validation of the key genes in signaling pathways related to short stature

According to the above experimental results, the GHR and WNT signaling pathways are relevant to the regulation of body growth. To obtain a reliable dataset for RNA-seq analysis, we conducted a series of in vitro experiments. Knockout or silencing of key genes to observe phenotypic changes is the primary strategy for verification experiments. GHR expression in long bone tissue was much lower in juvenile DPs than in MHs $(P<0.001)$ (Fig. 4a). Moreover, targeted GHR-RNAi constructs were selected for packaging according to the characteristics of the ATDC5 cell line from mice. When ATDC5 cells reached $80 \%$ confluence, the optimal multiplicity of infection (MOI) was approximately 10 (Additional file 7). Lentiviral knockdown experiments 


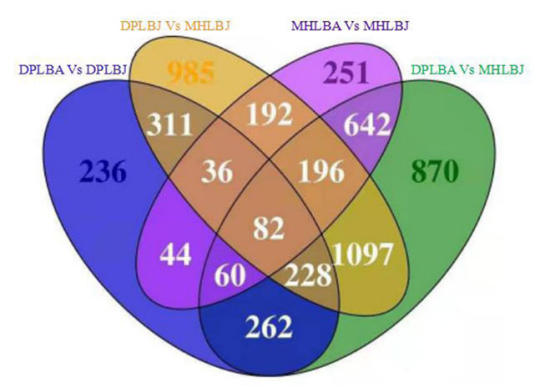

b

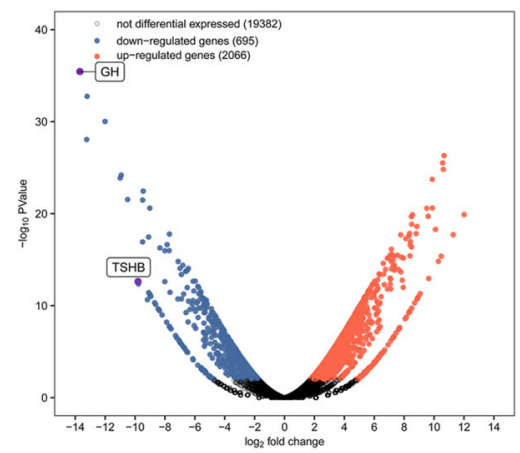

C
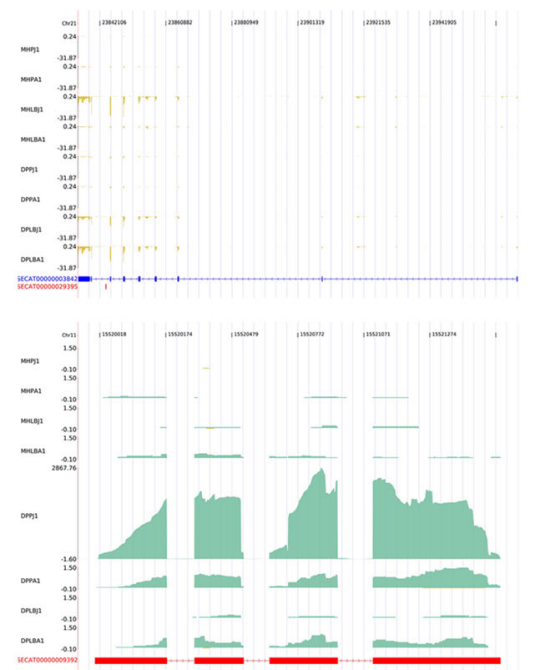
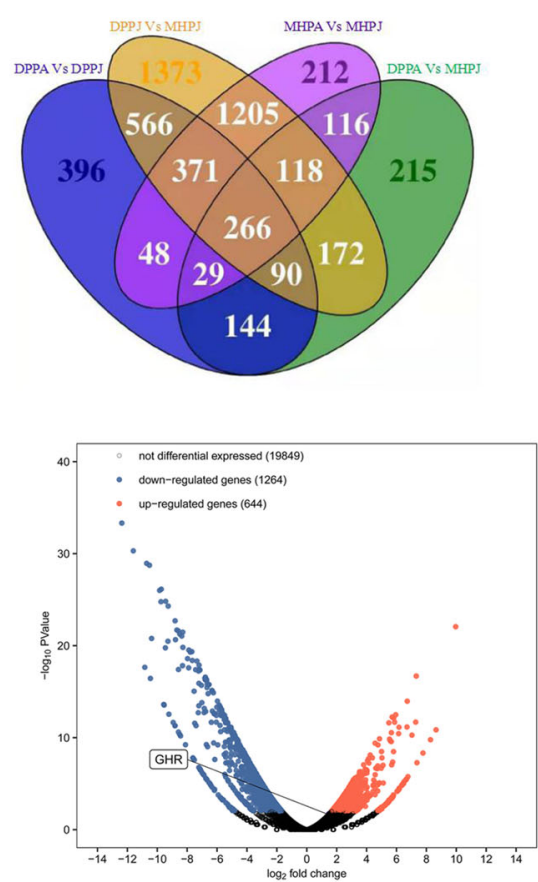

d
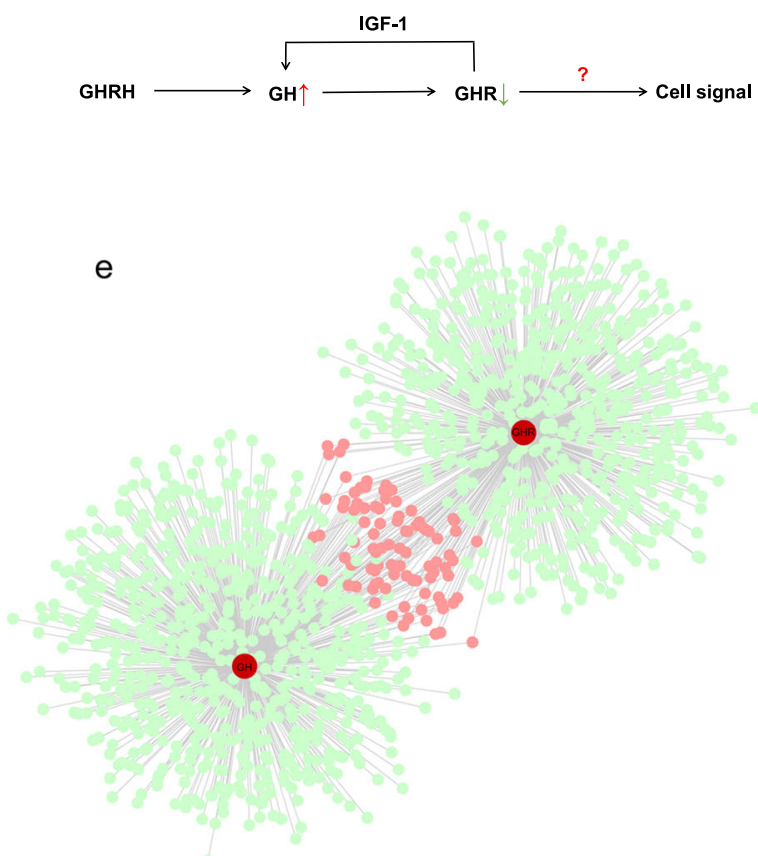

Fig. 2 Expression levels of GH and GHR genes in pituitary and epiphyseal tissues from Debao ponies and Mongolian horses, as determined by RNA-seq. a Venn diagram showing the numbers of the DEGs in the comparisons between pituitary and epiphyseal tissues between the two breeds. $\mathbf{b}$ Volcano plots highlighting the DEGs in blue $(P<0.05)$ and red $(q<0.05)$ for the DPPJ vs MHPJ and DPLBJ vs MHLBJ comparisons DPPJ, juvenile Debao pony pituitary; MHPJ, juvenile Mongolian horse pituitary; DPLBJ, juvenile Debao pony long bone; MHLBJ, juvenile Mongolian horse long bone. $\mathbf{c}$ Integrative Genomics Viewer visualization of GH and GHR gene RNA-seq data from the DP and MH pituitary and long bone tissue samples. Red indicates the reference gene tracks (ENSECAG00000002986 GHR;ENSECAG00000009392 GH); yellow and blue indicate the GHR and GH gene RNA-seq data tracks, respectively; the Y-axis shows the different samples; the X-axis shows a genome coordinate ruler that indicates the size of the region considered. $\mathbf{d}$ Interactions of $\mathrm{GH}$ and GHR and their effects on downstream cell signaling pathways. e The coexpression network linking GH and GHR revealed several key genes, such as ATF3, EGR3, SOX2, SOX5, and RUNX2 

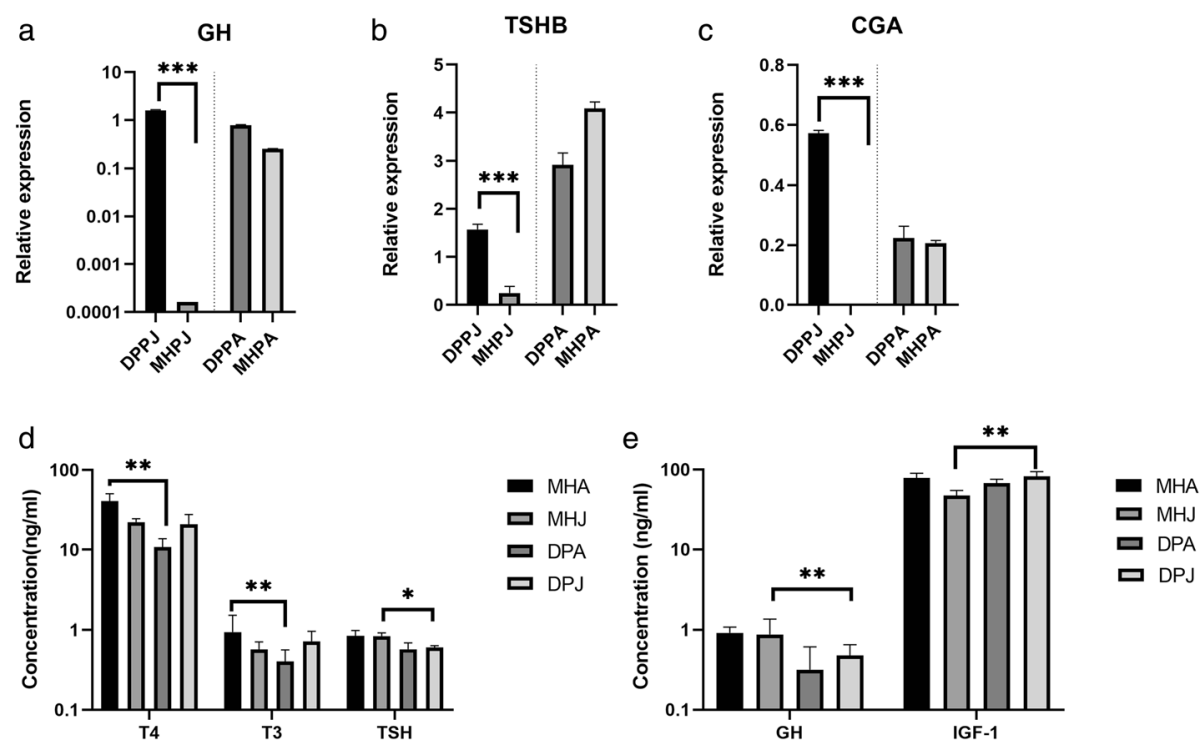

Fig. 3 Expression levels of key genes in pituitary tissues from Debao ponies and Mongolian horses. a Expression levels of GH genes in pituitary tissues from Debao ponies and Mongolian horses. $\mathbf{b}, \mathbf{c}$ Expression levels of TSHB and CGA in pituitary tissues from Debao ponies and Mongolian horses. $\mathbf{d}$ Determination of plasma T3, T4, and TSH concentrations in Mongolian horses and Debao ponies during the juvenile and adult stages. e Determination of plasma GH and IGF-1 concentrations of in Mongolian horses and Debao ponies during the juvenile and adult stages. ${ }^{*} P<0.01$, ${ }^{* *} P<0.05,{ }^{* * *} P<0.001$ )

showed that GHR expression in ATDC5 cells was significantly decreased after transfection (Additional file 8). The expression of the GHR, $m-R A S$ and ATF3 genes, which are related to the GHR pathway, in transfected cells was lower than that in untransfected cells $(P<0.05)$ (Fig. 4b). Furthermore, the apoptosis rate of the control cells was lower than that of the untransfected cells, and the apoptosis rate of the blank cells was lower than that of the GHR-knockdown cells. In contrast, the apoptotic rate of virus-transfected cells was relatively high $(P<0.05)$ (Fig. 4c, Additional file 9$)$.

The role of the WNT signaling pathway was verified in two cell lines, one of which was a horse bone marrow mesenchymal stem cell (BMSC) line. The other cell line used for validation was ATDC5. First, the cell line was obtained and identified: Highly active horse BMSCs were obtained, and the expression of the transcription factor Nanog and the surface markers CD44, CD90, and CD105

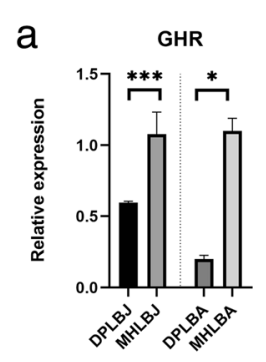

d

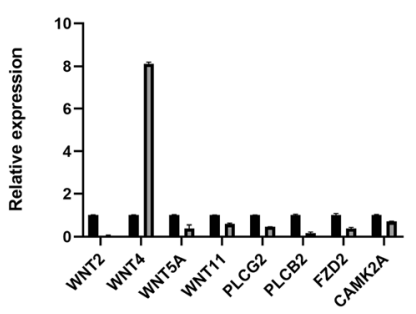

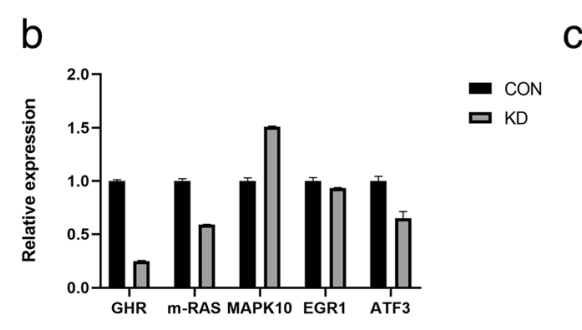
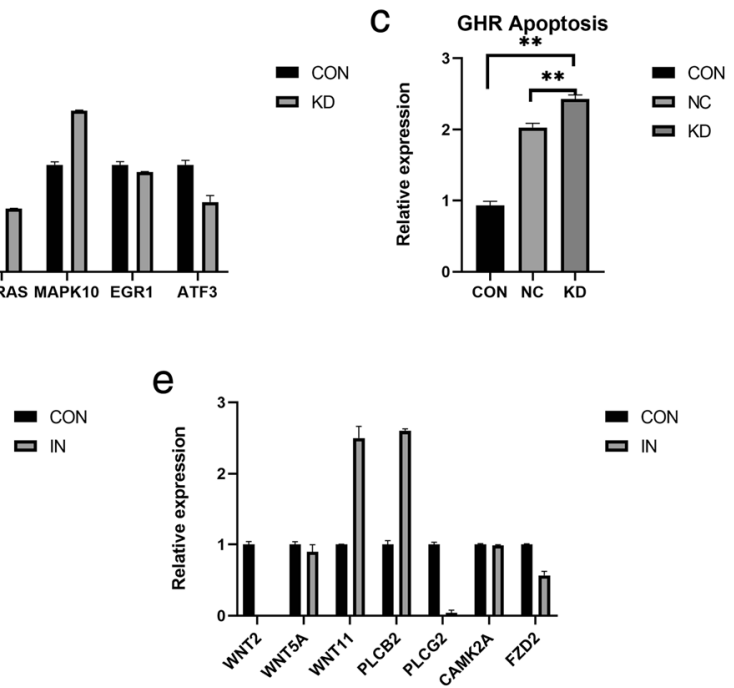

e

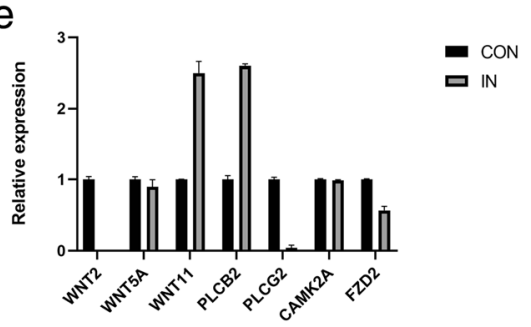

Fig. 4 Expression levels of key genes in the long bone epiphyseal tissues from Debao ponies and Mongolian horses. a Expression levels of GHR in long bone tissues from Debao ponies and Mongolian horses. b Expression of the GHR signaling pathway in a lentivirus-infected cell line. $\mathbf{c}$ Detection of apoptotic cells by FACS. $\mathbf{d}$ Gene expression in the WNT5A signaling pathway in osteoblasts. e Gene expression in the WNT5A signaling pathway in ATDC5 cells. $\left({ }^{*} P<0.01,{ }^{* *} P<0.05,{ }^{* *} P<0.001\right)$ 
in the cell line was determined. After induction and differentiation, the resulting osteoblasts were determined to be in good condition and became nodular (Additional file 10). Alizarin red stained the bone nodules formed by osteoblasts red, and Alcian blue stained the regions with accumulated proteoglycans and hyaluronic acid blue (Additional file 10). The expression of $C O L$ and ALPL in osteoblasts increased significantly with the increasing induction time (Additional files 11 and 12). Second, the expression of WNT pathway genes in osteoblasts induced for 14 days was detected by quantitative real-time PCR (qPCR) (Additional file 13). The expression of WNT5A and WNT2 gions osteoblasts decreased significantly $(P<0.05)$. However, CAMK2A expression did not change significantly, suggesting that the noncanonical WNT pathway might not be altered in the bone tissue of DPs (Fig. 4d). The expression of the WNT pathway genes in the ATDC5 cell line was similarly detected by q-PCR (Additional file 14), WNT4 expression was increased, although WNT11, WNT5A and WNT2 expression was decreased $(P<0.05)$; additionlly, FZD2, $P L C g 2$ and $P L C \beta 2$ expression was decreased in this cell line (Fig. 4e). In summary, these in vitro cell validation assays showed that the WNT5A and WNT2 genes acted through the PLC $\beta 2$ pathways via $W N T$ antagonists in ATDC5 cells and horse BMSCs.

In addition, we investigated whether alterations in upstream transcription factors or in SNPs in the key gene GHR. The sequences of all transcription factor genes from Equus caballus (Assembly EquCab3.0) were obtained from an animal transcription factor database (http://www.bioguo.org/AnimalTFDB). In total, 71 transcription factor genes were coexpressed with GHR, and 11 of these genes might play important roles in regulating the expression levels of GHR (Fig. 5a). In our study,

\section{a GHR growth hormone receptor [ Equus caballus(horse) ]}

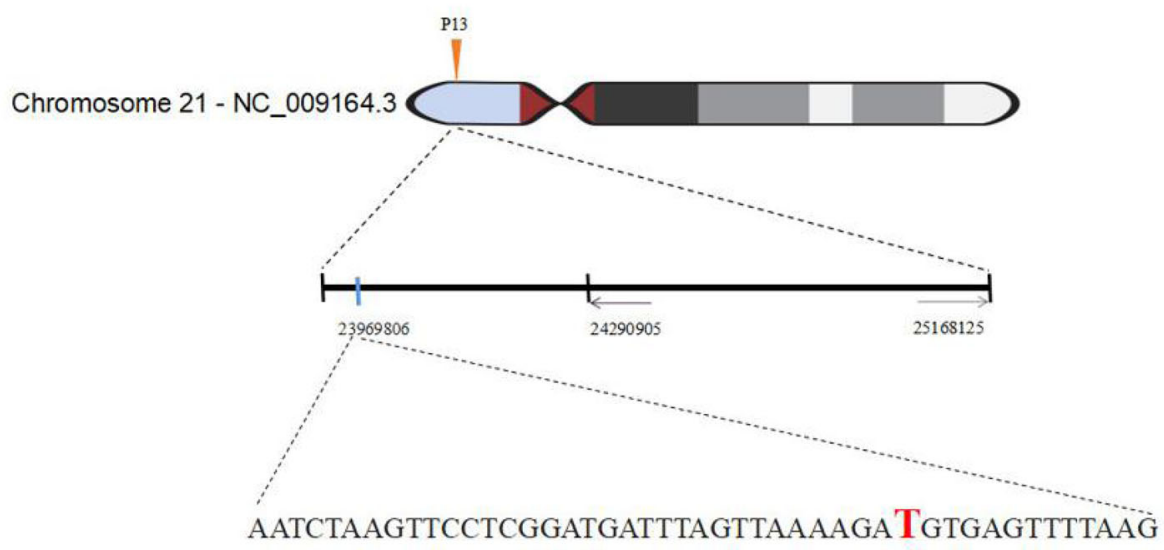

b

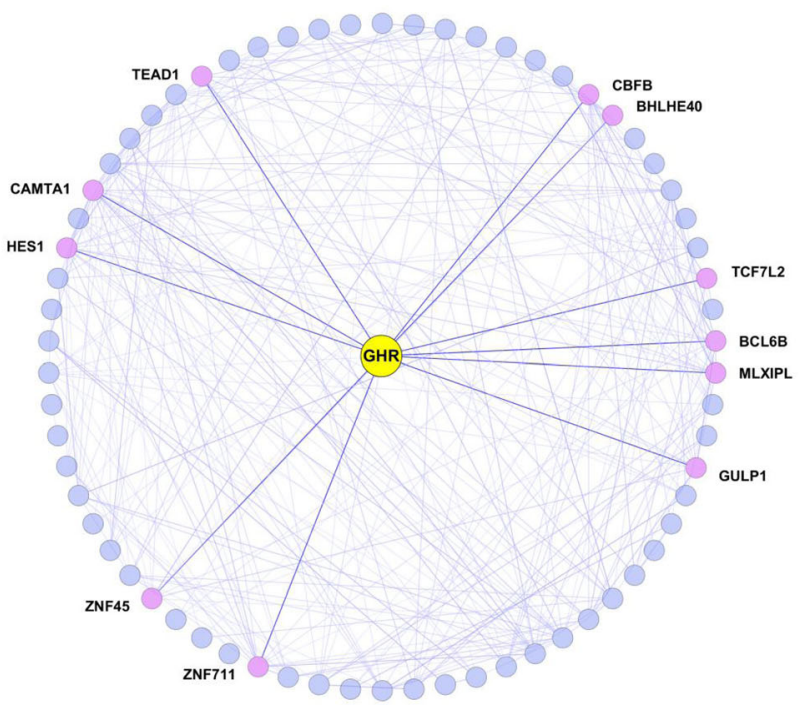

Fig. 5 Transcription factor genes that coexpressed with GHR in Debao ponies and Mongolian horses. a Transcription factor genes coexpressed with GHR and coexpression relationships in the long bone tissues from the two breeds. b Location of the SNP in the GHR of the Debao pony 
the $5000 \mathrm{bp}$ nucleotide sequence upstream of the GHR transcription start site was investigated in DPs and MHs. One SNP, a non-synonymous mutation chr21 23,969, 806 C-T of GHR (Fig. 5b) was found in DPs. Binding motifs analysis was performed, and the results revealed that SNPs led to differences in transcription factor binding motifs. This result implies that the SNP in GHR promoters might alter the binding motifs and lead to the different gene expression levels in the two breeds.

\section{Activation of bone signaling cascades is significantly altered in DPs}

On the basis of the transcriptome sequencing results between DP and MH pituitary and epiphyseal tissues, candidate genes were screened, and q-PCR and Western blot analysis were the used to verify the accuracy of the transcriptome data (Additional files 3, 4, 5 and 6). The transcriptome data were considered from a biogenetics perspective to determine the possible regulatory pathways controlling short stature in DPs. The above results indicated that in juvenile DPs, the pituitary gland secretes high levels of $\mathrm{GH}$, while the epiphyses exhibit a lack of GHR. GHR, $m-R A S$ and $A T F 3$, which are involved in the GHR pathway, were found to be significantly down regulated, by $75.2,41$ and $34.9 \%$, respectively, in ATDC5 cells with GHR-RNAi lentivirusmediated knockdown. Thus, bone growth in DPs may be inhibited via downregulation of the GHR pathway (Fig. 6a). However, WNT2,WNT5A,PLCg2 and FZD2 were noticeably downregulated, by $96.5,61,53.3$ and $61 \%$, respectively, in transfected ATDC5 cells. Such changes may increase the concentration of $\mathrm{Ca}^{2+}$ through WNT pathway activation and $\mathrm{Ca}^{2+}$ export from cells via solute carrier family 8 member A3 (SLC8A3) and

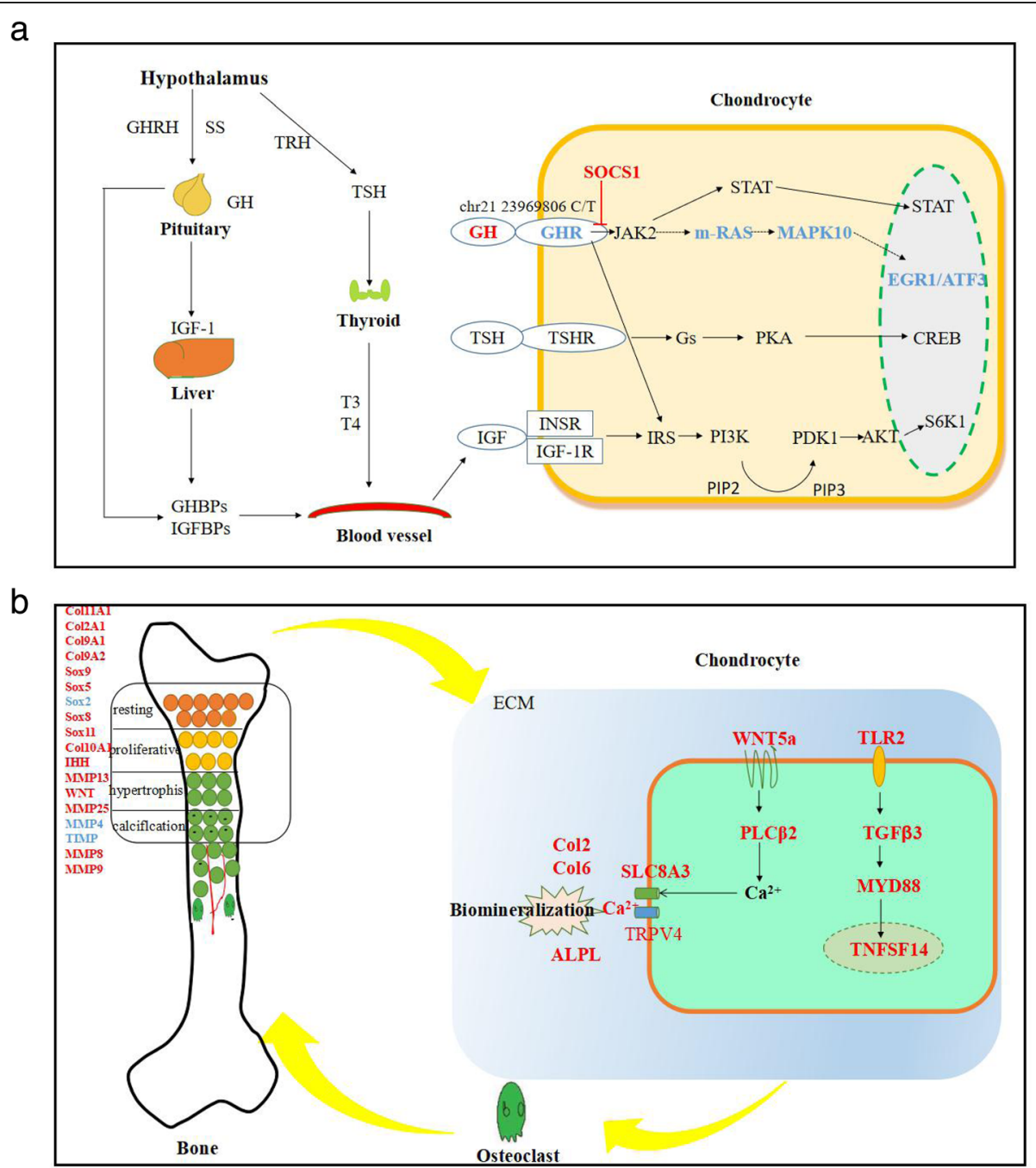

Fig. 6 Signaling pathways regulating short stature in the Debao pony. a The GHR signaling pathway regulates short stature in the Debao pony. $\mathbf{b}$ The WNT5A and TLR2 signaling pathways regulate short stature in the Debao pony. Genes with upregulated expression compared with that in the juvenile Mongolian horse are shown in red, while genes with downregulated expression are shown in blue 
transient receptor potential cation channel subfamily $\mathrm{V}$ member 4 (TRPV4) channels promote mineralization and early epiphyseal closure in coordination with changes in the expression of $A L P L$ and epiphyseal factors, and stimulate osteoclastogenesis to enhance bone resorption via the TLR pathway (Fig. 6b).

\section{Discussion}

Since 2007, when a draft genome of a thoroughbred mare was obtained, research on horses has entered a new era [19]. Gene expression levels in tissues from 8 breeds of horses were studied, and 75,116 transcripts were found, among which 20,302 protein-coding gene loci were accurately identified $[20,21]$. A highthroughput study on body size correlations in horses confirmed that many genes are closely related to body height [9-11]. In addition, a genome-wide scan of the X chromosome of the DP using an Equine SNP70 BeadChip revealed that five regions on the $\mathrm{X}$ chromosome are under strong selection. The candidate regions include SMS, DKC1, etc., which are involved in bone development, $\mathrm{GH}$ secretion and fat deposition; these genes may also be related to body height [22]. Furthermore, an Equine $70 \mathrm{~K}$ SNP genotyping array was used for genome-wide detection of copy number variations among domestic DPs, MHs and Yili horses, and 60, 42 and 91 genes were found to overlap with the breedspecific, respectively. Thus, these genes may be relevant to breed-specific traits [16]. A study using an Equine SNP 65 BeadChip also revealed that a new candidate gene, T-box transcription factor 3 (TBX3), exhibited the greatest differentiation and most significant association with body size among the examined genes and is thus likely to be the dominating factor controlling the small stature of the DP. TBX3 was elected independently in the DP, suggesting that there were multiple origins of small stature in horses [23]. However, these studies did not clearly reveal the molecular mechanism underlying short stature in the DP.

In this study, we selected MHs and DPs with different body heights for RNA-seq analysis and found that the expression levels of multiple genes were related to the heights of the two breeds. GHR expression in long bone tissue was 1.4-fold lower in DPs than in MHs, while GH expression was 13-fold higher, similar to the changes observed for dwarfism syndrome caused by familial dwarfism, idiopathic dwarfism and GHR mutation [17, 18] (Additional files 3 and 4). The routine treatment for these diseases is injection of recombinant $\mathrm{GH}$, but this often causes transient hyperglycemia, peripheral edema, fluid retention and other side effects. Therefore, research on short- stature animals with normal physiological activities can reveal the physiological mechanism underlying the small size phenomenon and aid in the development of treatments for dwarfism and other diseases.

In many patients, the short stature is caused by an imbalance in changes in the body's growth axis. The GHRH-GH-IGF axis, which is regulated by neuroendocrine factors, affects the growth and development of mammals. We thus collected the blood from these two breeds and measured hormone concentrations. We found that DPs exhibited unique physiological characteristics during the development of short stature, including high plasma IGF concentrations, low plasma GH concentrations, and high tissue GH expression levels. The results regarding plasma hormone levels were similar to those obtained for pygmies in Africa [24], but significantly different from those obtained for GHR-knockout animal models $[5,25]$. This discrepancy may be due to the differences between knockout mice and natural dwarfs. Notably, thyroid hormone is an important regulator of bone growth [26]. Our transcriptome data showed a significant difference in TSH levels but no difference in TSHR levels between the two horses at the juvenile stage. Specifically, the plasma TSH levels in juvenile DPs were lower than those in juvenile MHs, while the plasma T3 and T4 concentrations in adult DPs were higher than those in adult MHs. The expression of CGA in tissues was consistent with that of TSH [27]. CGA regulates synthesis and secretion by affecting T3 and indirectly mediates the role of TSH in DPs. These results indicated that a change in the TRH-TSH-T3T4 growth axis might be contributing of short stature in DPs; however, the expression of TSHR in the pituitary tissue of juvenile DPs was not altered. Therefore, TSH may not be the main driver of short stature in DPs.

The hormones secreted by the pituitary gland and the development of long bones directly determine the body size of animals. We found that $G H$ was highly expressed in pituitary and long bone tissues and that a lack of GHR expression in long bones may be the main cause of short stature in DPs. Although all GHRs function entirely through $G H$ signaling, they still cannot meet the needs for bone growth in juvenile DPs, which may lead to the short stature of these horses. This pattern of $G H R$, characterized by low expression and deficiency, is similar to that observed in many dwarfism diseases [17, 18]. Most studies on body size have addressed the physiological characteristics of GHR deficiency, but few have explained the causes of GHR deficiency. We further studied the SNPs in GHR and found that in DPs, GHR harbors SNP loci that may lead to its altered transcription. The GHR SNP in DPs identified in this study was located in the promoter region, and it may be influenced by environmental factors or epigenetic factors, including methylation, in evolutionary genetics. Therefore, we speculate that compared with other horses of normal 
body size, DPs may exhibit not only polymorphisms in key genes in the growth axis but also alterations in the relevant important signaling pathways.

The transcriptome data obtained in this study showed a significant difference in the expression of Suppressor of Cytokine Signaling 1 (SOCS1) in bone tissue between juvenile DPs and MHs and that the expression of SOCS1 was obviously increased in DPs. Moreover, SOCS family members, most prominently SOCS1, were upregulated in epiphyseal tissues of DPs. SOCS1 promotes ubiquitinmediated degradation of JAK2 [28]. SOCS2 is a key regulator of GHR sensitivity and is a GH-stimulated, STAT5b-regulated gene that acts in a negative feedback loop to downregulate GHR signaling [29].

Recent studies have made major strides in elucidating the mechanism of human JAK2 tyrosine kinase activation by GHR [30]. No significant differences in gene expression related to this pathway were identified in our study. However, we found that $G H$ and GHR may reduce the height of DPs by downregulating the MAPK signaling cascade. The $M A P K$ pathway is responsible mainly for the transcription of $A T F 3$, and studies have shown that ATF3 has a proapoptotic effect [31, 32]. In addition, the RNA-seq data revealed that the expression of EGR1, a zinc finger transcription factor-encoding gene located in the commonly deleted region (CDR) on chromosome 5q, was also decreased by the RNA-seq data. EGR1 has been found to play a role in promoting apoptosis or inhibiting growth in many cancer studies [33, 34]. Perhaps these two transcription factors inhibit the proliferation and transformation of chondrocytes in each region of the cartilage by reducing apoptosis, leading to slow chondrocyte growth and abnormal development.

Bone tissue development involves numerous signaling molecules and signal transduction pathways. These include mainly the bone morphogenetic protein (BMP), TGF $\beta 1$ and WNT protein families. We found that WNT5A and FZD2 expression in DPs was significantly upregulated compared with that in MHs (Fig. 4d). These genes belong to the noncanonical $W N T / \mathrm{Ca}^{2+}$ pathway, which is the main cell signaling pathway leading to $\mathrm{Ca}^{2+}$ deposition [35]. Thus, the levels of both intracellular and extracellular $\mathrm{Ca}^{2+}$ in DPs may be increased through the noncanonical WNT signaling pathway, leading to epiphyseal closure and cessation of growth. The expression of SLC8A3, TRPV4, TRPV5 and ALP in the long bone tissue of juvenile DPs was also obviously increased (Fig. 6b). SLC8A3 and TRPV4/5 are the key genes encoding $\mathrm{Ca}^{2+}$ transport channels on the cell membrane [36, 37]. ALP is the decisive factor leading to bone mineralization $[38,39]$. High expression of these genes in long bone tissue cells may increase $\mathrm{Ca}^{2+}$ transport, thus accelerating the mineralization of the osteoblast ECM.
In addition, significant changes were identified in $I H H$, MMP23/25/8/9/11, TIMP4, COL10A1, SOX9/6/5/8/11, COL2A1, COL9A1/2, COL11A1, SOX5, MMP11 and TIMP4. Except for SOX5, MMP11 and TIMP4, these genes were upregulated. The changes in these genes were consistent with changes in genes involved in cartilage development $[40,41]$. These results showed that the cells in the four regions of the epiphyseal plate changed rapidly under stimulation by the corresponding factors (Fig. 6b).

Studies have shown that the TLR2 and MyD88 pathways play an important role in bone loss caused by infection [42, 43]. Our results showed that the genes in inflammation-related signaling pathways were upregulated. TNFSF14 is also a member of the tumor necrosis factor receptor superfamily [44]. The protein encoded by this gene can promote transcription-related activation of proteins in osteoclasts, lead to the proliferation, growth, maturation and activation of osteoclasts, inhibit the proliferation and differentiation of osteoblasts, and promote the apoptosis of osteoblasts [45].

Molecular experiments showed that the collected horse bone marrow cells expressed the stem cell transcription factor Nanog and surface markers CD44, CD90 and CD105. According to previous literature, these markers are characteristic of BMSCs [46, 47]. q-PCR assays confirmed that COL2A1, COL1A2, COL6A1 and $A L P L$ (Additional file 11) were expressed in induced osteoblasts. As the induction time increased, the expression of most genes increased gradually, while COL1A2 expression peaked its maximum on the 21 st day, consistent with findings of Yoo et al. regarding $C O L$ expression [48]. The expression of $A L P L$ is used to evaluate the activity of osteoblasts, and high ALPL expression is considered a key indicators of osteoblast induction [49]. The expression of $A L P L$ increasing the induction time in the current study. However, due to the reduced activity of the induced cells,gene expression was not observed over 30 days. As the understanding of signaling pathways has expanded, an increasing number of scholars have used signaling pathway inhibitors to investigate the importance of pathways [50,51]. We selected WNT antagonistI as a blocker of the WNT signaling pathway according to the literature $[52,53]$ and determined the optimal concentration to improve the results.

\section{Conclusions}

The body size phenotype is the most direct manifestation of phenotypic differences among animals and is also a key characteristic used to identify livestock breeds. Our experiments showed that the important genes $M$ Ras and ATF3 in the GHR signaling pathway were downregulated in the DP, indicating that changes in this pathway may drive important functions in this breed. In 
addition, the expression of $P L C g 2$ in the WNT signaling pathway was increased, which could increase $\mathrm{Ca}^{2+}$ export from cells through the transporters TRPV4 and $S L C 8 A 3$ on the cell membrane. In addition, ECM, ALPL, IHH, MMP23, TIMP4, COL10A1, Sox9, Sox6, Sox8, Sox11, COL2A1, COL9A1 and other factors were found to promote the early occurrence of biomineralization and epiphyseal closure in juvenile DPs. These two pathways may mediate the development of short stature. The purpose of this study was to reveal the molecular mechanism of short stature by analyzing the difference in body height between DPs and MHs. Our findings provide insight into the genetic regulation of growth short stature in mammals and can be used as a reference for the development of therapeutic strategies for small size. However, the association of these signaling pathways with body size traits in ponies needs further validation.

\section{Methods}

\section{Collection of animal tissue samples}

Animals were killed at the slaughterhouse, and we collected the tissues for our study. The health of all animals included in the study, was assessed by local veterinarians. Pituitary glands and the ends of long bones were obtained from six heathy female DPs and six heathy female MHs (three juveniles and three adults per breed) for transcriptomic analysis. In addition, liver, pituitary gland and long bone epiphyseal tissues were obtained from six healthy female DPs and six healthy female MHs (three juveniles and three adults per breed) for q-PCR and Western blot analysis. Whole blood samples and plasma samples were collected from ten healthy DPs and ten healthy MHs (five juveniles and five adults per breed) for SNP detection and hormone content determination. All tissues and samples were immediately snap frozen in liquid nitrogen and stored at $-80{ }^{\circ} \mathrm{C}$ until further use.

\section{RNA extraction}

Each sample was individually ground (with a mortar and pestle under continuous liquid $\mathrm{N}^{2}$ chilling) into a fine powder before RNA extraction. Samples were stored at $-80^{\circ} \mathrm{C}$. Total RNA was extracted from $30 \mathrm{mg}$ of tissue by using the hot phenol method. In brief, cell pellets were resuspended and washed once in Buffer A $(50 \mathrm{mM}$ sodium acetate and $10 \mathrm{mM}$ EDTA, $\mathrm{pH}=5.2$ ). After collecting the cells by centrifugation, the pellets were resuspended in Buffer A containing 1\% SDS and immediately added to hot phenol. After incubation at $65^{\circ} \mathrm{C}$ for $5 \mathrm{~min}$ and centrifugation for $10 \mathrm{~min}$ at $4{ }^{\circ} \mathrm{C}$, the RNAcontaining supernatants were transferred to a new tube for ethanol precipitation, washed and dissolved in DEPC-treated water. The RNA was further purified with two phenol-chloroformextraction extraction steps and was then treated with RQ1 DNase (Promega) to remove DNA. The quality and quantity of the purified RNA were determined by measuring the absorbance ratio at $260 \mathrm{~nm} / 280 \mathrm{~nm}$ (A260/A280) using a SmartSpec Plus (Bio-Rad). The integrity of the RNA was further verified by $1.5 \%$ agarose gel electrophoresis [54].

Ribosomal RNA was removed from the RNA samples $(10 \mu \mathrm{g})$ using a RiboMinus rRNA Depletion Kit (Ambion), and the resulting samples were used to prepare directional RNA-seq libraries. The purified mRNA was then iron-fragmented at $95^{\circ} \mathrm{C}$ before being subjected to end repair and $5^{\prime}$ adaptor ligation. Then, reverse transcription (RT) was performed using RT primers containing a $3^{\prime}$ adaptor sequence and a randomized hexamers cDNA was purified and amplified, and all $200-500 \mathrm{bp}$ PCR products were purified, quantified and stored at $-80^{\circ} \mathrm{C}$ until they were used for sequencing.

\section{Processing of raw RNA-seq data and evaluation and alignment of clean data}

For high-throughput sequencing, libraries were constructed following the manufacturer's instructions, and an Illumina GAIIx system was used to collect data via $151 \mathrm{bp}$ single-end sequencing (ABlife Inc., Wuhan, China) [55]. Read quality was evaluated using FastQC [56]. Any reads less than $30 \mathrm{bp}$ in length were removed using Btrim (with a parameter setting of- $\mathrm{l}=$ 30) [57], and the remaining reads were used for further analysis. The reads were mapped to the horse genome (EquCab 3.0). The Salmon software (version 1.1.0) was used to map the reads to the reference cDNA sequences and calculate the transcript per million mapped reads value of each transcript using the quasi-mapping method [58].

\section{Analysis of DEGs}

To determine whether a gene was differentially expressed, we used the following thresholds: fold change $(\mathrm{FC})>2$ or $(\mathrm{FC})<-2$ and $P$-value $(\mathrm{P})<0.05$. The $P$ value for differential expression was calculated in the $R$ environment (version 3.6.3, https://www.r-project.org/) using the EdgeR package [59] (version 3.28.1), because it has good performance in the identification of DEGs from using biological triplicates [60]. EdgeR was downloaded from the Bioconductor website (www. bioconductor.org). To predict gene function and calculate the functional category distribution frequency, Kyoto Encyclopedia of Genes and Genomes (KEGG) and Gene Ontology (GO) analyses were employed using the Database for Annotation, Visualization and Integrated Discovery (DAVID) bioinformatics resource. 


\section{Validation by q-PCR}

In this study, q-PCR was performed on GHR and $G H$ to validate the validity of the RNA-seq data. The expression was normalized to that of the reference gene GAPDH [61]. The primers are described in Additional files 13 and 14. The same RNA samples used for RNA-seq were used for q-PCR. One microgram of RNA was reverse transcribed using a Prime Script ${ }^{\text {tm }}$ RT Reagent Kit (Takara) following the manufacturer's instructions. qPCR was performed in a Bio-Rad S1000 with Bestar SYBR Green RT-PCR Master Mix (DBI Bioscience) [62].

\section{Statistical analysis}

All data were analyzed using SPSS 20.0 (SPSS, Inc., Chicago, USA). For relative quantitation, the $\mathrm{F}=2^{-\Delta \Delta \mathrm{Ct}}$ method was used, where $2-\Delta \Delta C$ t reflected the relative expression level of the target gene in each sample relative to that in the control group. The remaining observations were paired; thus, a paired samples t-test was performed. $P<0.05$ was considered to indicate statistically significance.

\section{Construction of an RNAi lentiviral vector}

Based on the GHR gene sequence, we designed a sequence targeting the GHR gene for RNAi: 5 '- GCTG CAAGAATTGCTCATGAA - 3'. The GV493 vector (frame structure: hU6-CBh-gcGFP-IRES-puromycin, Shanghai Genechem Co., Ltd.) was used to construct the lentiviral vectors GV493-GHR-RNAi-a and GV493GHR-RNAi-b. Single-stranded primers containing AgeI and EcoRI restriction sites were synthesized. Doublestranded DNA was generated by primer annealing. T4 DNA ligase was used to ligate the double-restriction-site target vector, and the double-stranded DNA was annealed. Competent cells were then transformed and positive bacterial colonies were identified via PCR [63]. Plasmid extraction and sequencing were carried out and the qualified plasmids were used in the follow-up experiment.

\section{RNAi lentiviral packaging}

ATDC 5 cells were treated $24 \mathrm{~h}$ before transduction. The cell density was adjusted to $5 \times 10^{6}$ cells $/ 15 \mathrm{ml}$, and cells were cultured in a $10 \mathrm{~cm}$ cell culture dish at $37^{\circ} \mathrm{C}$ in $5 \%$ $\mathrm{CO}_{2}$. Cells were transduced at $70-80 \%$ confluence. Serum-free medium was added $2 \mathrm{~h}$ before transfection. The prepared DNA solution (GV vector plasmid, $20 \mu \mathrm{g}$; pHelper1.0 vector plasmid, $15 \mu \mathrm{g}$; pHelper2.0 vector plasmid, $10 \mu \mathrm{g}$ ) and transduction reagent (Shanghai Genechem Co., Ltd.) were added to centrifuge tubes to a total volume of $1 \mathrm{ml}$. The centrifuge tubes were incubated at room temperature for $15 \mathrm{~min}$, and the transduction mixtures were then added to ATDC5 cells and cultured for $6 \mathrm{~h}$. The culture medium containing the transfection mixture was then dicarded, and the cells were washed with $10 \mathrm{ml}$ of phosphate-buffered saline (PBS). Then, $20 \mathrm{ml}$ of serum was added to the cells, which were then cultured for 48-72 h. The ATDC5 cell supernatant was collected and centrifuged at $4{ }^{\circ} \mathrm{C}$ and $4000 \times \mathrm{g}$ for $10 \mathrm{~min}$. The supernatant was filtered through a $0.45 \mu \mathrm{m}$ filter and centrifuged at $4{ }^{\circ} \mathrm{C}$ and $25,000 \mathrm{r} / \mathrm{min}$ for $2 \mathrm{~h}$ and discarded. Virus preservation solution was added to resuspend the pellet and the solution was centrifuged at $10000 \mathrm{r} / \mathrm{min}$ for $5 \mathrm{~min}$. The supernatant was subpacked, and ATDC5 cells were cultured in 96-well plates $\left(4 \times 10^{4}\right.$ cells/well, $\left.100 \mu \mathrm{l}\right)$. Gradient dilutions of lentiviral particles were added, and cells were cultured for $24 \mathrm{~h}$. Then complete medium was added. The expression of fluorescent protein was observed after 4 days and the viral titer was calculated [64].

\section{Lentiviral transduction}

ATDC5 cells were subcultured at $80 \%$ confluence in 6 well plates $\left(3-5 \times 10^{4}\right.$ cells/well, $\left.2 \mathrm{ml}\right)$. ATDC5 cells at $20 \%$ confluence were infected with lentivirus. The cells were then divided into two groups: a negative control group and an RNAi lentivirus-infected group. Transduction was performed with and without puromycin. The culture medium was replaced after $16 \mathrm{~h}$ and the cells were photographed after $72 \mathrm{~h}[65]$.

\section{Apoptosis analysis}

Cells were treated with apoptosis assay kit resgents (eBioscience 88-8007), washed with ice-cold PBS, resuspended in binding buffer, and then incubated with Annexin V-APC for $10 \mathrm{~min}$ at room temperature in the dark. Finally, the apoptotic cells were analyzed by a FACS (Becton-Dickinson, USA).

\section{Isolation and culture of horse BMSCs}

BMSCs originally isolated from $\mathrm{MHs}$ were used in our laboratory at passage 3 (P3). After adult horses were slaughtered, the sternum was removed and sterilized with $75 \%$ alcohol. The following procedures were performed under sterile conditions. Two ends of the sternum were washed out with medium containing $1 \%$ penicillin and streptomycin in PBS, and the wash fluid was collected in $15 \mathrm{ml}$ sterile centrifuge tubes for centrifugation of at $1500 \mathrm{r} / \mathrm{min}$ for $5 \mathrm{~min}$. The supernatant was suspended in complete medium (DMEM/F-12 containing, $15 \%$ FBS, $0.1 \%$ penicillin, and $0.1 \%$ streptomycin) and inoculated in a flask at a density of $5 \times$ $10^{6}$ cells. The supernatant was cultured in an incubator at $37^{\circ} \mathrm{C}$, in $5 \% \mathrm{CO}_{2}$ and $100 \%$ humidity. After $48 \mathrm{~h}$, half of the supernatant was replaced. At $70-80 \%$ confluence, the cells were digested with trypsin and passaged at a ratio of 1:3. 
Induction of horse BMSCs differentiation into osteoblasts BMSCs at P3 cells were divided into an induction group and a noninduction group. The cells were $70-80 \%$ confluent, induction medium (osteogenic induction medium: $0.1 \mathrm{mM}$ dexamethasone, $10 \mathrm{mM}$ betaglycerophosphate disodium hydrate, $50 \mathrm{mg} / \mathrm{l} \mathrm{Vc}$ ) was added to the induction group. Cells were cultured for 28 days, and the medium was replaced every other day. The control undifferentiated group continued to be cultured in a general culture medium, and the cell state was photographed and noted daily.

\section{Alizarin red and Alcian blue staining}

After 7, 14 and 21 days of culture, Alizarin red and Alcian blue staining were performed on the induced and noninduced cells, respectively. When the cells were 70$80 \%$ confluent, they were washed with PBS 3 times for 2 min each and were then fixed with $4 \%$ paraformaldehyde at room temperature for $30 \mathrm{~min}$. The cells were then washed with PBS 3 times for 2 min each stained with solution for $5 \mathrm{~min}$ and washed again with PBS 3 times for 2 min each. Finally, the cells were visualized under the micoscope.

\section{MTT assay with ATDC5 cells and osteoblasts}

An MTT assay was used to evaluate cell proliferation. The mouse chondroprogenitor cell line ATDC5 was obtained from TongPai (Shanghai) Biotechnology Co., Ltd. Cells were cultured in a 96-well plate at a density of $1 \times$ $10^{5}$ cells $/ \mathrm{ml}$ and incubated in complete medium at $37^{\circ} \mathrm{C}$. After $24 \mathrm{~h}$, WNT antagonistIwas added to in serum-free medium at different concentrations, with 3 replicates per concentration. After $4 \mathrm{~h}$ of incubation, the medium was replaced with PBS, and $20 \mu \mathrm{l}$ of $20 \mathrm{mM}$ MTT was added and incubated for $3 \mathrm{~h}$ at $37^{\circ} \mathrm{C}$. After 3 $\mathrm{h}$, DMSO was added to dissolve the purple formazan crystals. The cell plates were placed on a horizontal shaker for $5 \mathrm{~min}$ to complete dissolution. The optical density was measured in an enzyme-linked immunoassay reader at an excitation wavelength of $490 \mathrm{~nm}$ [63]. Analyses were performed in triplicate.

\section{Supplementary Information}

The online version contains supplementary material available at https://doi. org/10.1186/s12864-020-07323-1.

Additional file 1:. Heights of the Debao pony and Mongolian horse at two developmental stages.

Additional file 2:. Sample correlation between tissues of Debao ponies and tissues of Mongolian horses.

Additional file 3:. Expression levels of $\mathrm{GH}$ in the pituitaries of Debao ponies and Mongolian horses.

Additional file 4:. Expression levels of GHR in the long bones of Debao ponies and Mongolian horses.
Additional file 5:. Expression of the $\mathrm{GH}$ protein in the pituitaries and long bones of Debao ponies and Mongolian horses.

Additional file 6:. Expression levels of IGF-1 in the livers of Debao ponies and Mongolian horses.

Additional file 7:. Easy-siRNA design; Infection was performed at different MOls. According to the efficiency of cell transduction, an $\mathrm{MOI}$ with a high infection efficiency that yielded a good cell status was selected. In ATDC5 cells at 70-80\% confluence, optimal infection was achieved with HiTransG P and an MOl of approximately 10.

Additional file 8:. GHR-RNAi expression in ATDC5 cells.

Additional file 9:. Detection of apoptosis by annexin V-APC staining.

Additional file 10:. Primary culture of horse BMSCs; electrophoresis of osteoblast marker genes, differentiation of osteoblasts, and Alizarin red (a and b) and Alcian blue (c and d) staining of horse induced BMSCs at day 28.

Additional file 11:. Induction of the expression of cartilage-specific genes on different days.

Additional file 12:. Primer sequences used for amplification of horse genes (PCR).

Additional file 13:. Primer sequences used for amplification of horse genes ( $q-P C R)$.

Additional file 14:. Primer sequences used for amplification of mouse genes (q-PCR).

\section{Abbreviations}

ALP: Alkaline phosphatase; ATF3: Activating transcription factor 3; ADAM TS17: ADAM metallopeptidase with thrombospondin type 1 motif 17; BMSCs: Horse bone marrow mesenchymal stem cells; BMP: Bone morphogenetic protein; DP: Debao pony; DPPJ: Juvenile Debao pony pituitary; DPPA: Adult Debao pony pituitary; DPLBJ: Juvenile Debao pony long bone; DPLBA: Adult Debao pony long bone; CAMKII: Calcium/ calmodulin dependent protein kinase II; COL6A1: Collagen type VI alpha 1 chain; COL2A1: Collagen type II alpha 1 chain; COL9A1: Collagen type IX alpha 1 chain; CGA: Glycoprotein hormones, alpha polypeptide; ECM: Extracellular matrix; EGR1: Early growth response 1; DKC1: Dyskerin pseudouridine synthase 1; FZD2: Frizzled class receptor 2; GH: Growth hormone; GHR: Growth hormone receptor; GHRH: Growth hormone releasing hormone.; HMGA2: High mobility group AT-hook 2; IGF-1: Insulinlike growth factors-1; ITPKC: Inositol trisphosphate 3 kinase C; IL8: Interleukin 8; JAK2: Janus kinase 2; MH: Mongolian horse; MHPJ: Juvenile Mongolian horse pituitary; MHPA: Adult Mongolian horse pituitary; MHLBJ: Juvenile Mongolian horse long bone; MHLBA: Adult Debao pony long bone; MMP: Matrix metalloproteinase; MYD88: MYD88 innate immune signal transduction adaptor; MAPK: Mitogen-activated protein kinase; $\mathrm{m}$ RAS: Muscle RAS oncogene homolog; OSTN: Osteocrin;

PLCB2: Phospholipase C beta 2; PLCg2: Phospholipase C gamma 2; qRTPCR: Quantitative real time polymerase chain reaction; RUNX2: Runt-related transcription factor 2; SNP: Single-nucleotide polymorphism; SMAD2: SMAD family member 2; STC2: Stanniocalcin 2; SMS: Spermine synthase; SLC8A3: Solute carrier family 8 member A3; SOCS1: Suppressor of cytokine signaling 1; TRPV4: Transient receptor potential cation channel subfamily $V$ member 4; TSHR: Thyroid stimulating hormone receptor; TIMP4: Tissue inhibitor of metallopeptidases 4; TNFRSF: Tumornecrosis factor receptor superfamily; TSH: Thyroid stlmulating hormone; TGF $\beta 3$ : Transforming growth factor beta 3; TLR2: Toll like receptor 2; TBX3: T-box transcription factor 3; WNT5A: WNT family member 5A

\section{Acknowledgments}

We are grateful for the necessary materials and valuable advice provided by F. Meng, Y. Liu, L. Li, T. Li, S. Wang, J. Pan et al. We also thank Wuhan ABlife Inc. for assisting with the bioinformatic analysis.

\section{Authors' contributions}

JF performed the experiments, analyzed the data, wrote and revised the manuscript, and prepared the figures and tables. DZ and HMZ conceived the study ideas and designed the experiments. YRZ was responsible for acquiring the funding. HYX and SCW performed the q-PCR and cell culture 
experiments. FW and $\mathrm{HMZ}$ supervised the manuscript writting process. JWC, $\mathrm{LZ}, \mathrm{CXL}, \mathrm{WW}$ and YPX collected the horse and pony samples. YL provided technical support for the bioinformatic analysis. All authors reviewed the manuscript. The author(s) read and approved the final manuscript.

\section{Funding}

This work was supported by the National Natural Science Foundation of China (31560621). The funding recipient (YRZ) was responsible for collecting the horse and pony samples.

\section{Availability of data and materials}

The data discussed in this publication have been deposited in the National Center for Biotechnology Information (NCBI) Sequence Read Archive and are accessible under GEO Series Accession No. GSE146145. We confirm that all experiments were carried out in accordance with the relevant guidelines and regulations.

\section{Ethics approval and consent to participate}

Horses were sampled with written consent from their owners under a protocol approved by the Biological Studies Animal Care and Use Committee of Neimenggu Province, China.

\section{Consent for publication}

Not applicable.

\section{Competing interests}

The authors declare that they have no competing interests.

\section{Received: 2 March 2020 Accepted: 14 December 2020} Published online: 18 January 2021

\section{References}

1. Zhang X, Chu Q, Guo G, Dong G, Li X, Zhang Q, Zhang S, Zhang Z, Wang Y. Genome-wide association studies identified multiple genetic loci for body size at four growth stages in Chinese Holstein cattle. PLoS One. 2017;12(4): e0175971. https://doi.org/10.1371/journal.pone.0175971 PMID: 28426785; PMCID: PMC5398616.

2. Lu HL, Xu CX, Jin YT, Hero JM, Du WG. Proximate causes of altitudinal differences in body size in an agamid lizard. Ecol Evol. 2017;8(1):645-54. https://doi.org/10.1002/ece3.3686 PMID: 29321901; PMCID: PMC5756846.

3. Cheng Y, Liu S, Su D, Lu C, Zhang X, Wu Q, Li S, Fu H, Yu H, Hao L. Distribution and linkage disequilibrium analysis of polymorphisms of $\mathrm{GH} 1$ gene in different populations of pigs associated with body size. J Genet. 2016;95(1):79-87. https://doi.org/10.1007/s12041-015-0611-0.

4. Reimer C, Rubin CJ, Sharifi AR, Ha NT, Weigend S, Waldmann KH, Distl O, Pant SD, Fredholm M, Schlather M, Simianer H. Analysis of porcine body size variation using re-sequencing data of miniature and large pigs. BMC Genomics. 2018;19(1):687. https://doi.org/10.1186/s12864-018-5009-y PMID: 30231878; PMCID: PMC6146782.

5. Hinrichs A, Kessler B, Kurome M, Blutke A, Kemter E, Bernau M, Scholz AM, Rathkolb B, Renner S, Bultmann S, Leonhardt $H$, de Angelis MH, Nagashima $H$, Hoeflich A, Blum WF, Bidlingmaier M, Wanke R, Dahlhoff M, Wolf E. Growth hormone receptor-deficient pigs resemble the pathophysiology of human Laron syndrome and reveal altered activation of signaling cascades in the liver. Mol Metab. 2018;11:113-28. https://doi.org/10.1016/j.molmet. 2018.03.006 Epub 2018 Mar 15. PMID: 29678421; PMCID: PMC6001387.

6. Wu S, Wang Y, Ning Y, Guo H, Wang X, Zhang L, Khan R, Cheng G, Wang H, Zan L. Genetic Variants in STAT3 Promoter Regions and Their Application in Molecular Breeding for Body Size Traits in Qinchuan Cattle. Int J Mol Sci. 2018;19(4):1035. https://doi.org/10.3390/ijms19041035 PMID: 29596388; PMCI D: PMC5979584.

7. Bouwman AC, Daetwyler HD, Chamberlain AJ, et al. Meta-analysis of genome-wide association studies for cattle stature identifies common genes that regulate body size in mammals. Nat Genet. 2018;50(3):362-7. https://doi.org/10.1038/s41588-018-0056-5.

8. Lango Allen $\mathrm{H}$, Estrada $\mathrm{K}$, Lettre $\mathrm{G}$, et al. Hundreds of variants clustered in genomic loci and biological pathways affect human height. Nature. 2010; 467(7317):832-8. https://doi.org/10.1038/nature09410.

9. Signer-Hasler H, Flury C, Haase B, Burger D, Simianer H, Leeb T, Rieder S. A genome-wide association study reveals loci influencing height and other conformation traits in horses. PLoS One. 2012;7(5):e37282. https://doi.org/10. 1371/journal.pone.0037282 Epub 2012 May 16. PMID: 22615965; PMCID: PMC3353922.

10. Metzger J, Rau J, Naccache F, Bas Conn L, Lindgren G, Distl O. Genome data uncover four synergistic key regulators for extremely small body size in horses. BMC Genomics. 2018;19(1):492. https://doi.org/10.1186/s12864-0184877-5 PMID: 29940849; PMCID: PMC6019228.

11. Norton EM, Avila F, Schultz NE, Mickelson JR, Geor RJ, McCue ME. Evaluation of an HMGA2 variant for pleiotropic effects on height and metabolic traits in ponies. J Vet Intern Med. 2019;33(2):942-52. https://doi.org/10.1111/jvim. 15403 Epub 2019 Jan 21. PMID: 30666754; PMCID: PMC6430908.

12. Moser SC, van der Eerden BCJ. Osteocalcin-A Versatile Bone-Derived Hormone. Front Endocrinol (Lausanne). 2019;9:794. https://doi.org/10.3389/ fendo.2018.00794 PMID: 30687236; PMCID: PMC6335246.

13. Brotto M, Bonewald L. Bone and muscle: Interactions beyond mechanical. Bone. 2015;80:109-14. https://doi.org/10.1016/j.bone.2015.02.010 PMID: 26453500; PMCID: PMC4600532.

14. Dugarjaviin M, Yang $\mathrm{H}$. Progress in the study of genetic diversity of Mongolian horse. Yi Chuan. 2008;30(3):269-76.

15. Li LF, Guan WJ, Hua Y, Bai XJ, Ma YH. Establishment and characterization of a fibroblast cell line from the Mongolian horse. In Vitro Cell Dev Biol -Animal. 2009:45:311-6.

16. Kader A, Liu X, Dong K, Song S, Pan J, Yang M, Chen X, He X, Jiang L, Ma Y. Identification of copy number variations in three Chinese horse breeds using 70K single nucleotide polymorphism bead Chip array. Anim Genet. 2016:47(5):560-9. https://doi.org/10.1111/age.12451.

17. Kang MJ. Novel genetic cause of idiopathic short stature. Ann Pediatr Endocrinol Metab. 2017;22(3):153-7. https://doi.org/10.6065/apem.2017.22.3. 153 Epub 2017 Sep 28. PMID: 29025200; PMCID: PMC5642075.

18. Fassone L, Corneli G, Bellone S, Camacho-Hübner C, Aimaretti G, Cappa M, Ubertini G, Bona MDG. Growth hormone receptor gene mutations in two Italian patients with Laron syndrome. J Endocrinol Investig. 2007;30:417-20. https://doi.org/10.1007/BF03346320.

19. Wade CM, Giulotto E, Sigurdsson S, et al. Genome sequence, comparative analysis, and population genetics of the domestic horse. Science. 2009; 326(5954):865-7. https://doi.org/10.1126/science.1178158.

20. Coleman SJ, Zeng Z, Hestand MS, Liu J, Macleod JN. Analysis of unannotated equine transcripts identified by mRNA sequencing. PLoS One. 2013;8(7):e70125. https://doi.org/10.1371/journal.pone.0070125 Erratum in: PLoS One. 2014;8(9). doi:10.1371/annotation/b9b4a26a-4eb1-482f-b99de248f8ca31fa. PMID: 23922931; PMCID: PMC3726457.

21. Coleman SJ, Zeng Z, Wang K, Luo S, Khrebtukova I, Mienaltowski MJ, Schroth GP, Liu J, MacLeod JN. Structural annotation of equine proteincoding genes determined by mRNA sequencing. Anim Genet. 2010; 41(Suppl 2):121-30. https://doi.org/10.1111/j.1365-2052.2010.02118.X.

22. Liu XX, Pan JF, Zhao QJ, He XH, Pu YB, Han JL, Ma YH, Jiang L. Detecting selection signatures on the $X$ chromosome of the Chinese Debao pony. J Anim Breed Genet. 2018;135(1):84-92. https://doi.org/10.1111/jbg.12314.

23. Kader A, Li Y, Dong K, Irwin DM, Zhao Q, He X, Liu J, Pu Y, Gorkhali NA, Liu $X$, Jiang L, Li X, Guan W, Zhang Y, Wu DD, Ma Y. Population Variation Reveals Independent Selection toward Small Body Size in Chinese Debao Pony. Genome Biol Evol. 2015;8(1):42-50. https://doi.org/10.1093/gbe/ evv245 PMID: 26637467; PMCID: PMC4758242.

24. Bozzola M, Travaglino P, Marziliano N, et al. The shortness of pygmies is associated with severe under-expression of the growth hormone receptor. Mol Genet Metab. 2009;98(3):310-3. https://doi.org/10.1016/j.ymgme.2009.05.009.

25. Venken K, Schuit F, Van Lommel L, et al. Growth without growth hormone receptor: estradiol is a major growth hormone-independent regulator of hepatic IGF-I synthesis. J Bone Miner Res. 2005;20(12):2138-49. https://doi. org/10.1359/JBMR.050811.

26. Baliram R, Latif R, Morshed SA, Zaidi M, Davies TF. T3 Regulates a Human Macrophage-Derived TSH- $\beta$ Splice Variant: Implications for Human Bone Biology. Endocrinology. 2016;157(9):3658-67. https://doi.org/10.1210/en. 2015-1974 Epub 2016 Jun 14. PMID: 27300765; PMCID: PMC5007892.

27. Bargi-Souza P, Romano RM, Goulart-Silva F, Brunetto EL, Nunes MT. T(3) rapidly regulates several steps of alpha subunit glycoprotein (CGA) synthesis and secretion in the pituitary of male rats: potential repercussions on TSH, FSH and LH secretion. Mol Cell Endocrinol. 2015;409:73-81. https://doi.org/ 10.1016/j.mce.2015.04.002.

28. Bunda S, Kommaraju K, Heir P, Ohh M. SOCS-1 mediates ubiquitylation and degradation of GM-CSF receptor. PLoS One. 2013;8(9):e76370. https://doi. org/10.1371/journal.pone.0076370 PMID: 24086733; PMCID: PMC3784415. 
29. Vesterlund M, Zadjali F, Persson T, Nielsen ML, Kessler BM, Norstedt G, FloresMorales A. The SOCS2 ubiquitin ligase complex regulates growth hormone receptor levels. PLoS One. 2011;6(9):e25358. https://doi.org/10.1371/journal. pone.0025358 Epub 2011 Sep 29. PMID: 21980433; PMCID: PMC3183054.

30. Ungureanu D, Wu J, Pekkala T, Niranjan Y, Young C, Jensen ON, Xu CF, Neubert TA, Skoda RC, Hubbard SR, Silvennoinen O. The pseudokinase domain of JAK2 is a dual-specificity protein kinase that negatively regulates cytokine signaling. Nat Struct Mol Biol. 2011;18(9):971-6. https://doi.org/10. 1038/nsmb.2099 PMID: 21841788; PMCID: PMC4504201.

31. Vert A, Castro J, Ribó M, Benito A, Vilanova M. Activating transcription factor 3 is crucial for antitumor activity and to strengthen the antiviral properties of Onconase. Oncotarget. 2017;8(7):11692-707. https://doi.org/10.18632/ oncotarget.14302 PMID: 28035074; PMCID: PMC5355296.

32. Weng S, Zhou L, Deng Q, Wang J, Yu Y, Zhu J, Yuan Y. Niclosamide induced cell apoptosis via upregulation of ATF3 and activation of PERK in Hepatocellular carcinoma cells. BMC Gastroenterol. 2016;16:-25. https://doi. org/10.1186/s12876-016-0442-3 PMID: 26917416; PMCID: PMC4766699.

33. Yoon TM, Kim SA, Lee DH, Lee JK, Park YL, Lee KH, Chuang IJ, Joo YE. EGR1 regulates radiation-induced apoptosis in head and neck squamous cell carcinoma. Oncol Rep. 2015;33(4):1717-22. https://doi.org/10.3892/or.2015.3747.

34. Li L, Zhao LM, Dai SL, Cui XW, Lv HL, Chen L, Shan BE. Periplocin extracted from cortex Periplocae induced apoptosis of gastric Cancer cells via the ERK1/2-EGR1 pathway. Cell Physiol Biochem. 2016;38(5):1939-51. https://doi. org/10.1159/000445555.

35. Wu X, Zhou S, Zhu N, Wang X, Jin W, Song X, Chen A. Resveratrol attenuates hypoxia/reoxygenation-induced $\mathrm{Ca} 2+$ overload by inhibiting the Wnt5a/Frizzled-2 pathway in rat H9c2 cells. Mol Med Rep. 2014;10:2542-8. https://doi.org/10.3892/mmr.2014.2488.

36. Julià A, González I, Fernández-Nebro A, et al. A genome-wide association study identifies SLC8A3 as a susceptibility locus for ACPA-positive rheumatoid arthritis. Rheumatology (Oxford). 2016;55(6):1106-11. https://doi. org/10.1093/rheumatology/kew035.

37. Wei Y, Wang Y, Wang Y, Bai L. Transient receptor potential Vanilloid 5 mediates $\mathrm{Ca} 2+$ influx and inhibits chondrocyte autophagy in a rat osteoarthritis model. Cell Physiol Biochem. 2017;42(1):319-32. https://doi. org/10.1159/000477387.

38. Misawa A, Orimo H. IncRNA HOTAIR inhibits mineralization in Osteoblastic osteosarcoma cells by epigenetically repressing ALPL. Calcif Tissue Int. 2018; 103(4):422-30. https://doi.org/10.1007/s00223-018-0434-0.

39. Ambroszkiewicz J, Chełchowska M, Szamotulska K, Rowicka G, Klemarczyk W, Strucińska M, Gajewska J. The Assessment of Bone Regulatory Pathways, Bone Turnover, and Bone Mineral Density in Vegetarian and Omnivorous Children. Nutrients. 2018;10(2):183. https://doi.org/10.3390/nu10020183 PMID: 29414859; PMCID: PMC5852759.

40. Hoch JM, Mattacola CG, Medina McKeon JM, Howard JS, Lattermann C. Serum cartilage oligomeric matrix protein (sCOMP) is elevated in patients with knee osteoarthritis: a systematic review and meta-analysis. Osteoarthritis Cartilage. 2011;19(12):1396-404. https://doi.org/10.1016/j.joca. 2011.09.005 Epub 2011 Oct 5. PMID: 22001901; PMCID: PMC3962955.

41. Boyle WJ, Simonet WS, Lacey DL. Osteoclast differentiation and activation. Nature. 2003;423(6937):337-42. https://doi.org/10.1038/nature01658.

42. Makkawi H, Hoch S, Burns E, Hosur K, Hajishengallis G, Kirschning CJ, Nussbaum G. Porphyromonas gingivalis Stimulates TLR2-PI3K Signaling to Escape Immune Clearance and Induce Bone Resorption Independently of MyD88. Front Cell Infect Microbiol. 2017;7:359. https://doi.org/10.3389/fcimb. 2017.00359 PMID: 28848717; PMCID: PMC5550410.

43. Yu X, Hu Y, Freire M, Yu P, Kawai T, Han X. Role of toll-like receptor 2 in inflammation and alveolar bone loss in experimental peri-implantitis versus periodontitis. J Periodontal Res. 2018;53(1):98-106. https://doi.org/10.1111/ jre.12492 Epub 2017 Sep 5. PMID: 28872184; PMCID: PMC5760345.

44. Wong BR, Josien R, Choi Y. TRANCE is a TNF family member that regulates dendritic cell and osteoclast function. J Leukoc Biol. 1999;65(6):715-24. https://doi.org/10.1002/jlb.65.6.715.

45. Dougall WC, Glaccum M, Charrier K, Rohrbach K, Brasel K, De Smedt T, Daro E, Smith J, Tometsko ME, Maliszewski CR, Armstrong A, Shen V, Bain S, Cosman D, Anderson D, Morrissey PJ, Peschon JJ, Schuh J. RANK is essential for osteoclast and lymph node development. Genes Dev. 1999;13(18):2412-24. https://doi. org/10.1101/gad.13.18.2412 PMID: 10500098; PMCID: PMC317030.

46. Mildmay-White A, Khan W. Cell surface markers on adipose-derived stem cells: a systematic review. Curr Stem Cell Res Ther. 2017;12(6):484-92. https://doi.org/10.2174/1574888X11666160429122133.
47. Gale AL, Linardi RL, McClung G, Mammone RM, Ortved KF. Comparison of the Chondrogenic differentiation potential of equine synovial membranederived and bone marrow-derived Mesenchymal stem cells. Front Vet Sci. 2019;6:178.

48. Yoo HJ, Yoon SS, Park SY, Lee EY, Lee EB, Kim JH, Song YW. Gene expression profile during chondrogenesis in human bone marrow derived mesenchymal stem cells using a cDNA microarray. J Korean Med Sci. 2011; 26(7):851-8. https://doi.org/10.3346/jkms.2011.26.7.851 Epub 2011 Jun 20. PMID: 21738335; PMCID: PMC3124712.

49. Jo S, Han J, Lee YL, Yoon S, Lee J, Wang SE, Kim TH. Regulation of osteoblasts by alkaline phosphatase in ankylosing spondylitis. Int J Rheum Dis. 2019;22(2):252-61. https://doi.org/10.1111/1756-185X.13419.

50. Aodengqimuge, Liu S, Mai S, Li X, Li Y, Hu M, Yuan S, Song L. AP-1 activation attenuates the arsenite-induced apoptotic response in human bronchial epithelial cells by up-regulating $\mathrm{HO}-1$ expression. Biotechnol Lett. 2014;36(10):1927-36. https://doi.org/10.1007/s10529-014-1560-z.

51. Kulik G. ADRB2-Targeting Therapies for Prostate Cancer. Cancers (Basel). 2019;11(3):358. https://doi.org/10.3390/cancers11030358 PMID: 30871232; PMCID: PMC6468358.

52. Poorebrahim M, Sadeghi S, Rahimi H, Karimipoor M, Azadmanesh K, Mazlomi MA, Teimoori-Toolabi L. Rational design of DKK3 structure-based small peptides as antagonists of Wnt signaling pathway and in silico evaluation of their efficiency. PLoS One. 2017;12(2):e0172217. https://doi. org/10.1371/journal.pone.0172217 PMID: 28234935; PMCID: PMC5325476.

53. Janda CY, Dang LT, You C, Chang J, de Lau W, Zhong ZA, Yan KS, Marecic O, Siepe D, Li X, Moody JD, Williams BO, Clevers H, Piehler J, Baker D, Kuo CJ, Garcia KC. Surrogate Wnt agonists that phenocopy canonical Wnt and $\beta$-catenin signalling. Nature. 2017;545(7653):234-7. https://doi.org/10.1038/ nature22306 Epub 2017 May 3. PMID: 28467818; PMCID: PMC5815871.

54. Qiao Y, Wang R, Yang X, Tang K, Jing N. Dual roles of histone H3 lysine 9 acetylation in human embryonic stem cell pluripotency and neural differentiation. J Biol Chem. 2015;290(4):2508-20. https://doi.org/10.1074/jbc M114.603761. Epub 2014 Dec 17. Erratum in: J Biol Chem. 2015 Apr 17; 290(16):9949. PMID: 25519907; PMCID: PMC4303699.

55. Song Q, Yi F, Zhang Y, Jun Li DK, Wei Y, Yu H, Zhang Y. CRKL regulates alternative splicing of cancer-related genes in cervical cancer samples and HeLa cell. BMC Cancer. 2019;19(1):499. https://doi.org/10.1186/s12885-0195671-8 PMID: 31133010; PMCID: PMC6537309.

56. Brown J, Pirrung M, McCue LA. FQC dashboard: integrates FastQC results into a web-based, interactive, and extensible FASTQ quality control tool. Bioinformatics. 2017:33(19):3137-9. https://doi.org/10.1093/bioinformatics/btx373.

57. Kong Y. Btrim: a fast, lightweight adapter and quality trimming program for next-generation sequencing technologies. Genomics. 2014;98(2):152-3.

58. Patro R, Duggal G, Love MI, Irizarry RA, Kingsford C. Salmon provides fast and bias-aware quantification of transcript expression. Nat Methods. 2017; 14(4):417-9.

59. Robinson MD. McCarthy DJ, and Smyth GK edgeR: a bioconductor package for differential expression analysis of digital gene expression data. Bioinformatics. 2010;26(1):139-40.

60. Schurch NJ, Schofield P, Gierlinski M, Cole C, Sherstnev A, Singh V, Wrobel N, Gharbi K, Simpson GG, Owen-Hughes T, Blaxter M, Barton GJ. How many biological replicates are needed in an RNA-seq experiment and which differential expression tool should you use? RNA. 2016;22(6):839-51.

61. Parker RA, Clegg PD, Taylor SE. The in vitro effects of antibiotics on cell viability and gene expression of equine bone marrow-derived mesenchymal stromal cells. Equine Vet J. 2012;44(3):355-60.

62. Islam R, Matsuzaki K, Sumiyoshi E, Hossain ME, Hashimoto M, Katakura M, Sugimoto $\mathrm{N}$, Shido $\mathrm{O}$. Theobromine improves working memory by activating the CaMKII/CREB/BDNF pathway in rats. Nutrients. 2019;11(4):888.

63. Kumar P, Nagarajan A, Uchil PD. Analysis of Cell Viability by the MTT Assay. Cold Spring Harb Protoc. 2018;2018(6). https://doi.org/10.1101/pdb.prot095505.

64. Giry-Laterrie're M, Verhoeyen E, Salmon P. Lentiviral vectors. Methods Mol Biol. 2011;737:183-209.

65. Lizee G, Aerts JL, Gonzales MI, Chinnasamy N, Morgan RA, Topalian SL. Realtime quantitative reverse transcriptase-polymerase chain reaction as a method for determining lentiviral vector titers and measuring transgene expression. Hum Gene Ther. 2003;14:497-507.

\section{Publisher's Note}

Springer Nature remains neutral with regard to jurisdictional claims in published maps and institutional affiliations. 